Send your letters to the editor, British Dental Journal, 64 Wimpole Street, London W1G 8YS E-ail bdj@bda dentistry.org.uk Priority will be given to letters less than 500 words long. Authors must sign the letter, which may be edited for reasons of space

\section{Consumers and healthcare}

Sir,- I should like the opportunity to respond to your thought-provoking leader, 'A matter of taste' (BDJ 2003, 195: 293) concerning the implications of consumerism for dentistry.

In thirty years of dentistry, I have always been keenly aware of the need to address the psychological needs of patients.

This can take many forms, but relevant to the subject under discussion here is the need to inform, explain, discuss, answer queries and advise in relation to a patient's care, and to give that patient the benefit of whatever choice exists.

My experience of relating to patients in this way over the years has taught me that these necessary aspects of my work can meet with varying levels of success. We live in an age of readily available information, and we hunger for information in order to make appropriate choices.

It can therefore be easy, via popular press or Internet, for example, for patients to acquire a little learning, time-honoured as possibly being a dangerous thing.

If information is to be of any value, it must first be understood by the recipient, and then processed along with other items of information in fully appraising a situation, and then making a decision about it. Full understanding comes from the combined exercise of knowledge and intelligence.

Decision making involves an extension of this, but in the case of patients making healthcare decisions, there will nearly always be significant emotional factors in addition, which, rightly or wrongly, may influence their decision.

Without wishing to sound unkind or patronising, it is an inescapable fact of life that we all have a different mix of talents, and it must be common experience that some of our patients are not, and never will be, capable of fully understanding the subtleties, nuances, technicalities and complexities of dentistry, even if we were to try and give them a 'crash course' in their particular dental problem.
Even very intelligent patients often lack sufficient dental knowledge to allow them readily to understand the finer points relevant to their treatment.

It does, after all take five years to train a dentist, even to basic qualification level. Whilst one might have a good chance of success explaining the technicalities of bridgework if one's patient is a civil engineer, the same might not be expected of a doctor of theology.

And I am sure we will all have encountered patients for whom all regions distal to the canines are as familiar as the far side of the moon! If one adds to the shortfall in knowledge or ability to understand, the amount of prejudice, myth, misinformation, mistrust and suspicion which many patients hold about dentists and dentistry, it is easy to appreciate how complex and difficult it can be for us to relate meaningfully to our 'consumers', and vice versa.

Patients sometimes approach us with preconceived ideas, and request inappropriate solutions to what they see as their needs. Telling us what they want is fine, and desirable. But having patients telling us how they want us to achieve what they want is not good news. Some patients can be very insistent, and are unwilling to be advised otherwise.

I sometimes wonder whether such patients, if asked whether they would like their treatment plan to be drawn up by an unqualified person, would give an affirmative answer! But I am not, here, promoting the dictatorial, paternalistic approach of yesteryear, as I believe in selfdetermination for patients, in agreement with your editorial.

Self-determination is a basic human right, but like all the other rights and freedoms we hold dear, it comes inextricably linked to personal responsibility. Consequently, consumerism in healthcare is a doubleedged sword. For patients to be involved in decision making about their dental care is good, but patients cannot expect to be absolved from the responsibilities which go with those decisions, and which belong fairly and squarely in their court.

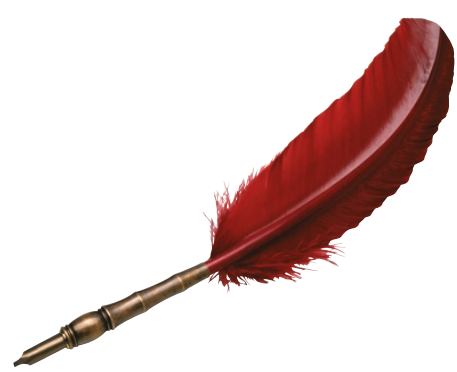

Dentistry, like the rest of human activity, is not risk-free. If a patient has treatment explained, accepts it, has it carried out to a good standard, and then becomes disappointed with the outcome because they did not understand the explanation, or had undisclosed unrealistic expectations, but 'went ahead anyway with fingers crossed,' whose fault is it?

The dentist's fault for not painting a black enough picture? Or the patient's for failing to understand? Similarly, should we always tell patients what we think they need to know, and risk blinding them with science in the process, or should we wait for them to ask questions, hoping and praying that they ask the right ones to keep us out of court? Or to cover all eventualities, perhaps we should do both?

Either way, it can become very complicated, takes time and patience on the part of all concerned, sometimes needs to be repeated, and often, one feels, would be prudently put in writing! Not so long ago, a well-known consultant psychiatrist, popular in the media, pointed out that even when people are given wellconstructed, rational arguments illustrating clearly that some aspects of their behaviour are unhealthy or undesirable for them, and despite those people understanding the arguments and agreeing with the conclusions, their undesirable behaviour often continues unchanged ('It won't happen to me').

Patients can and do make healthcare decisions in the face of clearly demonstrable evidence that mitigates against those decisions. The pervading concept in your editorial is that of 'taste'.

I would like to add two similar words to the discussion. 'Truth' and 'trust'. These are particularly relevant with respect to the point you raise regarding 'professionalism versus commercialism', and whether we should follow the lead taken by the rest of society. Just because something is 'new', it does not automatically mean it is 'better', nor does it mean it is 'good'.

The Advertising Standards Authority requires that advertisements be 'legal, decent, honest and truthful'. The mere fact 
that such an institution exists to ensure this, logically indicates that some advertisements would not meet these requirements without such regulation, and the Authority has already made an adverse judgement involving dentistry, in the case of a dentist's advertisement deemed inappropriately to use the title of 'Doctor', a situation which, I would suggest, was entirely predictable.

There is a great deal of psychology involved in advertising and marketing, which makes it possible to convey a desirable impression to the consumer, and to the vendor's advantage, not by telling lies exactly, but by economising with the truth.This suggests deception, which I would hope we would not want to be associated with any field of human endeavour which calls itself a profession. An advertisement may promote a treatment as if it were suitable for everyone, but it may not be so.

It may tell no lies. It may tell only truth, but is it truth 'full'? I do not disagree with the professions, including ours, being permitted to advertise, but they must do so with caution and responsibility. The reason is very simple. Professions, traditionally, have expected, and continue to expect, the respect, honour and trust of the public. I personally feel it would be impossible for me to treat patients without their trust. If we do not demonstrate honour and truthfulness, we have no right to expect trust.

If we wish our patients to trust us, and that can be difficult enough already, let us not risk the abandonment of truth by allowing it to be cosily diluted or sacrificed on the altar of the individual's definition of 'good taste'.

Otherwise, we will be inviting abuse, and human nature being what it is, that is precisely what we will get, and the result will be the erosion of our cherished professional standing.Traditionally, the professions have been charged with the responsibility of setting and upholding standards of behaviour and moral values for the rest of society. We are expected to be role models. Are we now to give up that role and determine our behaviour along the lines exhibited by 'the rest', some examples of whom can be seen on popular television audience participation programmes, expounding their views, exposing their prejudices, parading their self-interest, and are enough to undermine the thinking persons' faith in democracy? I hope not.

Within the last year, we have received the report of the Office of Fair Trading, which called for a number of improvements in the way our profession relates to its consumers. I would suggest that some of the shortfalls highlighted could be attributed directly to the profession's inclination to follow business practices which might otherwise be associated with the less reputable.

Rather than taking our lead from the rest, should we not, as professionals, be helping to form the vanguard and setting examples for them to follow instead? I conclude with a modified quotation: 'There are lies, damned lies, statistics.... and advertising'.... if you're not careful. Ars...Scientia...Mores?

\section{G.Raven}

Birmingham

doi: 10.1038/sj.bdj.4810799

\section{Fees for specialists}

Sir,- Mr Tidy's letter (BDJ 2003, 195: 423) raises some questions about the GDC's charging of a fee for specialists on the orthodontists and oral surgeons, and queried the arrangements for erasure for non-payment. At its meeting in June the Council decided to suspend charging fees to orthodontists and oral surgeons.

The General Dental Council is a nonprofit making organisation; the organisation does not make profits. The power to charge a fee is clearly provided for in Regulation 5(1) of the European Primary and Specialist Dental Qualifications Regulations 1998 and the GDC's 1998 regulations.

The cost of registering specialists was high in the past years due to the transitional arrangements. Now that transition is almost completed the cost of retention is reduced. The $£ 40$ quoted by Mr Tidy is the cost of providing registration services shared equally among all type of registrants. The power to erase someone from the specialist lists for non-payment of the fee is clearly set out in the 1998 regulations.

\section{A. Townsend}

Chief Executive \&t Registrar

GDC

doi: $10.1038 /$ sj.bdj.4810800

\section{Overbrushing challenge}

Sir,- At last, E Harrison has had the courage to denounce the plethora of articles on 'overbrushing' (BDJ 2003, 195: 361). Although I am just a GDP, over thirty years of practicing I have seen the negative effects of patients who brush too gently. There are not many people who can brush effectively using a soft brush, with gentle force. Materia alba, let alone plaque, is the most common sequel to this 'technique'. My verbal oral hygiene instruction to patients has changed over the years from complicated brushing techniques, to my current advice, which is 'give them a good scrub ... you cannot brush too hard'.

I am 55yrs old and have personally used this method and have no gingival recession and no calculus formation. Whilst accepting that one case is not statistical evidence, surely, gingival recession in the face of firm brushing is genetic, but poor, gentle brushing is bound to lead to gingival and periodontal disease.

\section{E. E. Thompson}

Sutton Coldfield

doi: 10.1038/sj.bdj.4810801

\section{Prevention}

Sir, - I thought the article on age-related prevention (BDJ 2003, 195: 237) was an excellent article, which will give much encouragement to those involved in treating such cases. I would like to add a few comments from my own experience with chlorhexidine to complement it.

In my practice I use a typical custommade bleaching tray, filled with chlorhexidene gel, and kept in the mouth for an hour each night for two weeks. The patient will then require a hygiene appointment, and can be monitored as mentioned.

If necessary this can be repeated many times, without time consuming surgery visits. I find this is effective for all age ranges, indeed the idea came from a paediatric lecture I attended. I would like to take issue with the authors in their acceptance of caries left deliberately under a crown. I have seen too many instances where even with the best intentions this has lead to disaster.

Finally, I found the relative caries risk of bridging compared with removable appliances is most encouraging.

\section{L. Harris}

Oxford

The author responds: Thank you for your comments. I was particularly interested in Dr Harris'suggestion for tray-based delivery of chlorhexidine gel, which I was not familiar with. It would appear to me to be an eminently sensible way to apply gel but further research would be needed to evaluate the technique.

With reference to the suggestion of sealing caries under a crown, to be clear, I was not suggesting that caries be left under indirect restorations but that dentine affected but uninfected by caries could be left within the body of an intracoronal preparation provided the preparation was restored with a material that effectively sealed the tooth restorative 
interface. I hope this clarifies the confusion with respect to this.

\section{A Brunton \\ Oxford}

doi: $10.1038 /$ sj.bdj.4810802

\section{Buyers beware!}

Sir,- Recent assessments of the risk of transmission of vCJD via surgical instruments and dentistry have placed great emphasis on the efficacy of routine cleaning and sterilisation of instruments to minimise the risks of transmission of infectious agents ${ }^{1}$. Reviews on the efficacy of cleaning and sterilisation undertaken in dental practice have highlighted several shortcomings, particularly in the cleaning of instruments.

Most, if not all, dental practices employ an element of manual cleaning of the instruments. Manual cleaning is inefficient, laborious, time consuming (and therefore expensive) and places the user at-risk from sharps injuries and splatter with infectious material.

Ultrasonic cleaners can have a role to play providing they are adequately maintained and frequently tested (weekly) to ensure that they still work.

Following ultrasonication, instruments should be rinsed and may require further cleaning prior to sterilisation. One solution to reducing risks to dental personnel and patients should be an automated cleaning process that is efficient, safe, reproducible and cost effective - devices that achieve this have been used in sterile service departments for many years and are referred to as 'washer disinfectors'

In the UK, criteria for the validation, testing and safe operation of these devices are defined in Health Technical Memoranda (HTM or its Scottish equivalent SHTM), HTM/SHTM 2030 specifically relating to washer disinfectors.

The forthcoming European standard EN 15883 Part I, is expected to augment the best practice guidance given in HTM/SHTM 2030. The recent increased focus on decontamination practice has led to an increase in the range of benchtop washer disinfectors that are commercially available. To ensure the efficacy of cleaning and disinfection, the entire process must be validated - in effect this means that these machines must meet the technical criteria detailed in (HTM/SHTM 2030).

In order to avoid practitioners wasting well earned funds, I would strongly recommend that practitioners obtain a written assurance from the supplier that the washer disinfector: a. is CE marked,

b. complies with British standard (BS)

2745

c. complies with HTM (or SHTM) 2030

Part 2

d. will comply with EN 15883 Part 1

(which is expected to come into effect in early 2004).

e. will be provided with monitoring of the washer disinfector cycle

independent of the process controller,

for example, printed record of cycle.

Practitioners should be aware that in order to comply with these requirements it is also necessary for the machine to be commissioned on installation and subjected to daily, weekly, quarterly and annual testing. Dental practitioners should be fully conversant with these requirements prior to committing the practice to an automated cleaning device.

There is a need for clear and concise guidelines on the purchase and operation of these devices from the relevant professional and technical regulatory bodies for dental practitioners.

Automated washer disinfectors will do much to reduce the risks of transmission of infectious agents but will come at a cost. Prior to purchasing such devices practitioners should ask some tough questions, otherwise, judging from the current market place, a lot of money will be spent on products that fail to meet the required technical standards.

A. Smith
Glasgow

doi: $10.1038 /$ sj.bdj.4810803

1. www.doh.gov.uk/cjd/dentistryrisk/index.htm

\section{CPD papers}

Sir,- I read with a wry smile the letter from Dr I Storrar (BDJ 2003, 195:230) regarding the $B D J /$ Eastman CPD. May I also as a more mature GDP (Leeds 1961) raise my voice in praise of the Eastman CPD verifiable papers.

They have provided an opportunity for one who is unable now to assimilate the information and world of academia, and I am grateful that I am able to learn and relearn many aspects of general dental surgery. I do find it sad that Dr Storrar finds it neccesary to start at the end and flick back to the beginning. Did he read as a child great works of fiction in a similar manner? He should remember that he will be old one day and in a similar position to myself - to enjoy CPD in comfort. To quote the late great Winston Churchill 'They also serve who merely sit and wait' (read)!

M. Killourhy

Doncaster

doi: 10.1038/sj.bdj.4810804 